\title{
Effect of a Three-month Period of Diet and pPhysical Activity on Adipokines and Inflammatory Status in Children with Metabolic Syndrome
}

\author{
RAMONA STROESCU1,3, OTILIA MARGINEAN ${ }^{1,3}$, TEOFANA BIZEREA ${ }^{1,3,}$, MIHAI GAFENCU1,3, ADRIAN VOICU2*, \\ GABRIELA DOROS ${ }^{1,3}$, ANIKO MANEA ${ }^{4}$, MARILENA MOTOC ${ }^{5}$ \\ 'Victor Babes University of Medicine and Pharmacy, Department of Pediatrics, 2 Eftimie Murgu Sq., Timisoara 300041, Romania \\ 2Victor Babes' University of Medicine and Pharmacy, Department of Medical Informatics and Biostatistics, 2 Eftimie Murgu Sq., \\ 30004, Timisoara, Romania \\ ${ }^{3}$ Louis Turcanu Emergency Hospital for Children, 2 Iosif Nemoianu Str., 300011, Timisoara, Romania \\ ${ }^{4}$ Victor Babes University of Medicine and Pharmacy, Department of Neonatology and Puericulture, 2 Eftimie Murgu Sq., 300041, \\ Timisoara, Rómania \\ ${ }^{5}$ Victor Babes University of Medicine and Pharmacy, Department of Biochemistry and Pharmacology, 2 Eftimie Murgu Sq., \\ 300041, Timisoara, Romania
}

\begin{abstract}
The prevalence of metabolic syndrome (MetS) in the young population continues to rise. This study aimed to determine whether adipokines are significant markers in defining MetS in a pediatric population and to assess the effect of a hypocaloric diet and physical activity on serum concentrations of adiponectin, leptin, and high-sensitivity C-reactive protein (hs-CRP). A prospective study was conducted over a period of 1 year, between January and December 2015, on 66 cases of obesity in children diagnosed at the Louis Turcanu Emergency Hospital for Children in Timisoara, Romania. The patients diagnosed with MetS were put on diet and physical exercise for 3 months. MetS was present in $63.6 \%$ of obese children. There was a significant and positive correlation between MetS and both leptin and hs-CRP and a significant, negative correlation between MetS and adiponectin. After diet and physical activity, 3 patients no longer met the criteria for MetS. Leptin, adiponectin and hs-CRP concentrations statistically improved after a three-month diet and physical activity program. In conclusion, hs-CRP, leptin and adiponectin can be used as predictors of cardiovascular risk in the pediatric population. Diet and physical activity have an impact on metabolic status
\end{abstract}

Key words: metabolic syndrome, leptin, adiponectin, hs-CRP.

As the obese population continues to rise, the prevalence of MetS is increasing in both children and adolescents [1] Prevalence of MetS and its components increases strongly with age, but, unfortunately, it can also be diagnosed in infants. As indicated in previous studies, children and adolescents with risk factors such as obesity, dyslipidemia, elevated blood pressure and impaired glucose metabolism are at increased risk of developing atherosclerosis in adulthood [2, 3]. It has been found that obesity results in the early onset of chronic disease more typical of adulthood, such as cardio-cerebrovascular disease [4].

The role of inflammation in the progression of atherosclerosis and the susceptibility to cardiovascular events is well known. The possible role of CRP in the atherosclerotic process is very complex [5]. CRP facilitates the adhesion and migration of monocytes into the arterial wall and has an inhibitory effect on nitric oxide synthesis, resulting in altered vascular reactivity $[6,7]$. The hs-CRP assay can accurately detect lower protein concentrations with greater sensitivity than the standard PCR detection assay. The idea that adipose tissue is just a form of energy storage has changed dramatically in recentyears. Currently, adipose tissue is considered to be a true endocrine gland that fulfills multiple roles in regulating different biological functions. Communication between adipose tissue and other systems is accomplished through bioactive mediators (adipokines) [8]. Adipokines control energy homeostasis through metabolic, endocrine and immunological pathways. Adipose tissue is strongly linked to leptin levels. There are strong correlations between leptin concentrations and both body fatmass and adipocyte size. Leptin acts on receptors in the hypothalamus, primarily in the arcuate nucleus, in order to limit food intake and raise energy expenditure.

Leptin resistance might be an explanation as to why in obesity, despite high leptin concentrations, appetite is not reduced.

Leptin is an established risk factor for atherosclerosis, stimulating the secretion of proinflammatory cytokines such as interleukin 6 and TNF a [9]. In contrast to leptin, adiponectin concentrations are inversely correlated with body fat mass. Its actions are anti-inflammatory, antiatherogenic and antidiabetic [10]. Adiponectin plays major roles in insulin sensitization and energy metabolism. Circulating levels of adiponectin are low in obese patients, especially in those with abdominal obesity; adiponectin levels increase when patients begin to lose weight [6]. Serum adiponectin levels were associated with age, sex (lower in men, possibly due to the androgenic effect) and smoker status. The reduction of fat mass improves insulin sensitivity, reduces the levels of inflammation markers and ameliorates endothelial dysfunction, consequently slowing down the development of diabetic complications.

\section{Experimental part}

Material and methods

A prospective study was conducted over a period of 1 year, between January 2015 and December 2015, on 66 cases of obesity in children diagnosed at the Louis Turcanu Emergency Hospital for Children in Timis oara. The patients diagnosed with MetS were put on a three-month diet and physical exercise for 3 months. Subjects were considered obese on the basis of age-specific BMI reference guidelines 
from the Centers for Disease Control and Prevention Child Growth Standards 2000 (above the 95th percentile).

MetS was defined using Weiss criteria [10]. No changes to the method were made after the start of the trial. hsCRP was determined by immunonephelometry from serum samples and processed in a BN ProSpec ${ }^{\circledR}$ system (Siemens Healthcare Diagnostics Inc.) (undetected if $<0.02 \mathrm{mg} / \mathrm{dL}$ ).

Quantitative measurements of serum leptin and adiponectin levels were performed using commercially available enzyme-linked immunosorbent assay kits (Antisel and Diamedix).

Exclusion criteria were obesity caused by endocrine disease, syndromic obesity, systemic disease or acute illness.

We analyzed 66 patients diagnosed with obesity. The data are expressed as means \pm standard deviation or as frequencies. Statistical analysis was conducted with SPSS $v .20$ and the R v.3.2.3 software packages. A p-value $<0.05$ was considered statistically significant.

All methods were carried out in accordance with the relevant guidelines and regulations of the ethical committee of the hospital and the declaration of Helsinki. All experimental protocols were approved by the ethical committee of the Louis Turcanu Emergency Hospital for Children. Informed consent documentation was signed by the parents in Romanian for all subjects.

The descriptive statistics (number of cases $\mathrm{N}$, range, minimum and maximum values, mean values) for the anthropometric and metabolic characteristics of the obese group are shown in table 1.

Table 1

DESCRIPTIVE STATISTICS FOR: BMI, SBP , DBP AND HSCRP

\begin{tabular}{|c|c|c|c|c|c|}
\hline & $\mathrm{N}$ & $\begin{array}{l}\text { Rang } \\
\mathrm{e} \\
\end{array}$ & $\begin{array}{l}\text { Mini } \\
\text { mum }\end{array}$ & $\begin{array}{l}\text { Maxi } \\
\text { mum }\end{array}$ & Mean \\
\hline Age (years) & 66 & 13 & 5 & 18 & 11.82 \\
\hline sex & 66 & 1.0 & 1.0 & 2.0 & 1.485 \\
\hline BMI kg/m2 & 66 & 26.00 & $\begin{array}{l}22.0 \\
0\end{array}$ & 48.00 & 30.54 \\
\hline $\mathrm{SBP} \mathrm{mmHg}$ & 66 & 50 & 108 & 158 & 127.59 \\
\hline $\mathrm{DBP} \mathrm{mmHg}$ & 66 & 48 & 59 & 107 & 77.73 \\
\hline $\begin{array}{l}\text { Cholesterol } \\
\mathrm{mmol} /\end{array}$ & 66 & 3.00 & 2.00 & 5.00 & 3.6364 \\
\hline LDLc mmol/l & 66 & 2.00 & 1.00 & 3.00 & 2.0455 \\
\hline $\mathrm{HDLc} \mathrm{mmol} / \mathrm{l}$ & 66 & 1.00 & .00 & 1.00 & .6212 \\
\hline $\begin{array}{l}\text { Baseline } \\
\text { glucose } \\
\text { mmol/l }\end{array}$ & 66 & 3.00 & 3.00 & 6.00 & 4.2879 \\
\hline $\begin{array}{l}\text { 2hglucose } \\
\mathrm{mmol} /\end{array}$ & 66 & 8.00 & 3.00 & 11.00 & 6.1970 \\
\hline $\begin{array}{l}\text { Adiponect } \\
\mathrm{ug} / \mathrm{ml}\end{array}$ & 66 & 65.00 & .00 & 65.00 & 19.2424 \\
\hline Lept ng/ml & 66 & 60.00 & 5.00 & 65.00 & 25.1515 \\
\hline $\mathrm{hsCRP} \mathrm{mg} / \mathrm{dl}$ & 66 & 10.0 & .0 & 10.0 & 7.621 \\
\hline MetS & 66 & 1 & 0 & 1 & .61 \\
\hline
\end{tabular}

\section{Results and discussions}

Due to a large number of combinations between variables, the matrix of correlations is very complex and difficult to interpret. For this reason, we preferred a graphical representation of all the available variables, in $R$, using the corrgram package. The result can be seen in Figure 1. The colors and sizes of circles vary according to the intensity of correlations. The variable of interest in this case is MetS. The graph results in a significant and positive correlation between MetS and hs-CRP and a significant, negative correlation between MetS and adiponectin.

Data modeling was also done in R 3.5 [11].

Since the MetS dependency variable is of binomial type (we have assigned values of 0 for the absence or 1 for the presence of MetS), we decide on used a generalized linear model using the glm function. Applying the model with all variables included, we obtained the following output:

Call:

glm(formula $=$ MetS ${ }^{~}$, data $=$ smet $)$

Coefficients:

Estimate Std. Error t value $\operatorname{Pr}(>|t|)$

(Intercept) 8.389e-02 8.107e-01 0.1030 .918

age -4.173e-03 1.456e-02 -0.287 0.776

sex 6.671e-02 8.861e-02 0.7530 .455

BMI 3.670e-04 8.465e-03 0.0430 .966

SBP 2.568e-03 4.251e-03 0.6040 .549

DBP -4.172e-03 4.553e-03 -0.916 0.364

chol -1.517e-03 8.403e-02 -0.018 0.986

LDLC 6.933e-02 8.910e-02 0.7780 .440

HDLC -2.241e-02 1.399e-01 -0.160 0.873

BasalGlucose -6.343e-02 1.090e-01 -0.582 0.563

2hglucose $-5.559 \mathrm{e}-03$ 2.979e-02 -0.1870 .853$

adiponect $-8.291 \mathrm{e}-03$ 1.597e-03 -5.191 4.01e-06 ***

lept 7.614e-04 3.381e-03 0.2250 .823

hs-CRP 1.118e-01 1.232e-02 9.070 4.64e-12 ***

Signif. codes: 0 '***' $0.001^{\prime} * * *^{\prime} 0.011^{\prime} *{ }^{\prime} 0.05$ '.' $0.1^{\prime \prime}$ ' 1

(Dispersion parameter for gaussian family taken to be $0.07724573)$

Null deviance: 15.758 on 65 degrees of freedom

Residual deviance: 3.785 on 49 degrees of freedom

AIC: 34.632

Number of Fisher Scoring iterations: 2

As noted above, the adiponectin and hs-CRP variables are relevant to our model $(p<0.05)$, consistent with the graphical representation of the correlations between variables (fig. 1)

To remove the less relevant variables (overfitted model), we penalized the model using the Akaike Information Criterion (AIC) and the stepwise regression algorithm. The result is shown below:

Call:

glm(formula $=$ MetS $\sim$ BasalGlucose + adiponect + hsCRP, data $=$ smet )

Deviance Residuals:

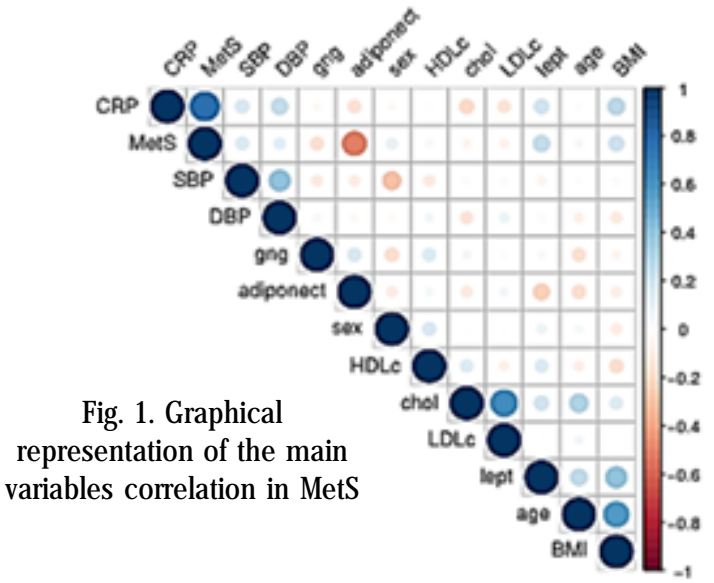


Min 10 Median 3Q Max

$\begin{array}{llll}-0.71060 & -0.11029 & 0.00283 & 0.072120 .55868\end{array}$

Coefficients:

Estimate Std. Error t value $\operatorname{Pr}(>|t|)$

(Intercept) 0.3343440 .2960991 .1290 .263

BasalGlucose $-0.0889000 .059550-1.4930 .141$

adiponect $-0.0086540 .001374-6.2983 .47 \mathrm{e}-08 * * *$

hs-CRP $0.1091060 .01016210 .7378 .90 \mathrm{e}-16 * * *$

Signif. codes: 0 '***' $0.001^{\prime * * \prime} 0.01^{\prime} *$ ' $0.05^{\prime \prime . '} 0.1^{\prime \prime}$ ' 1

(Dispersion parameter for gaussian family taken to be 0.06605784 )

Null deviance: 15.7576 on 65 degrees of freedom

Residual deviance: 4.0956 on 62 degrees of freedom

AIC: 13.837

Number of Fisher Scoring iterations: 2

As seen in the model above, MetS is positively influenced by hs-CRP (intercept $=0.109106, p=10.7378 .90 \mathrm{e}-16$ ).

Adiponectin has a protective effect (Intercept $=-0.008654$ and $p=-6.298$ 3.47e-08).

Basal glucose has a lower effect, below the statistically significant limit $(p<0.05)$.

AIC is thus reduced from 34. 632 to 13. 837. A smaller value for AIC means a better model.

The binomial model also allowed us to calculate Odd Ratio OR for adiponectin and hs-CRP:

$\begin{array}{lc}\text { (Intercept) } & \text { OR } \\ \text { adiponectin } & 1.39702 \\ \text { hs-CRP } & 0.99138 \\ & 1.11528\end{array}$

hsCRP favours the occurrence of MetS $(O R>1)$, while adiponectin has a protective effect $(O R<1)$.

A density plot of CRP and adiponectin according to the presence (1) and the absence ( 0 ) of MetS is illustrated in figures 2 and 3 , respectively.

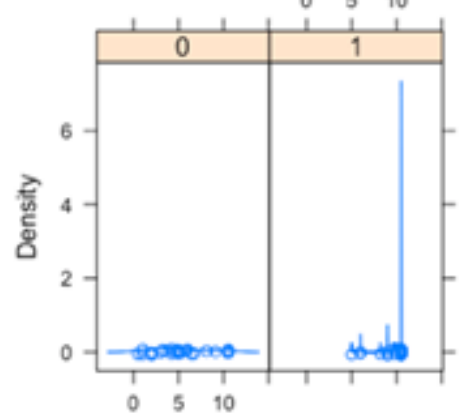

Fig. 2. Density plot of hs-CRP

CRP

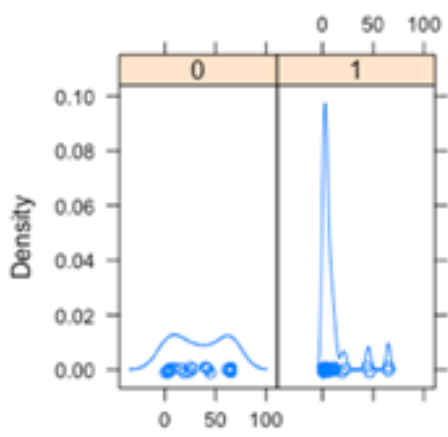

adiponect

\begin{tabular}{|l|l|l|l|l|}
\hline & $\begin{array}{l}95 \% \text { Confidence Interval } \\
\text { of the Difference }\end{array}$ & t & df & Sig. (2-tailed) \\
\hline Pair 1 BMI1 - BMI3 & 1.6521 & 8.350 & 41 & 0.000 \\
\hline Pair 2 hs-CRP1 - hs-CRP3 & 1.0258 & 13.846 & 41 & 0.000 \\
\hline Pair 3 leptin1 - leptin3 & 14.97123 & 9.252 & 41 & 0.000 \\
\hline $\begin{array}{l}\text { Pair 4 adiponectin1 - } \\
\text { adiponectin3 }\end{array}$ & -.82661 & -5.735 & 41 & 0.000 \\
\hline
\end{tabular}

REV.CHIM.(Bucharest) $\$ 70 \diamond$ No.1 2019

http://www.revistadechimie.ro activity over a period of 3 months. The results of a paired samples t-test for the anthropometric and biological changes are shown in table 2 .

Interpreting the output:

The variables considered were: BMI, hs-CRP, adiponectin, leptin, at baseline and after 3 months.

We used the paired t test with 41 degrees of freedom W1) 2 tailed, 95\% Confidence Interval of the Difference. For BMl: The mean value of BMI decreases from 31.98 to 30.65 ; $t(41)=8.35 p<0.001$. This was statistically highly significant.

For leptin: The mean value of leptin decreases from 28.32 to $16.03 ; t(41)=9.252 p<0.001$. This was statistically highly significant.

For Hs-CRP: The mean value of hs-CRP decreases form 9.955 to $9.060 ; t(41)=13.846 p<0.001$. This was statistically highly significant.

For adiponectin: The mean value of adiponectin increases from 9.77 la $11.04 ; t(41)=-5.74 p<0.001$.This was statistically highly significant.

The greatest effect was observed on CRP, (reflected by the highest value for $t(41)=13.846$.

Obesity is a chronic inflammatory disorder, in which leptin, adiponectin and CRP play an important role. The present study proposes an assessment of the importance of various adipogenic factors (adipokines, inflammation) as incipient risk factors for atherosclerosis in the pediatric population. The atherosclerotic profile can be improved by diet and physical activity. We studied a group of children with obesity and divided the group according to the presence or absence of MetS. The group with MetS was puton a dietand physical activity for three months. Changes in adiponectin, leptin and hs-CRP concentrations following this period were measured. There were statistically significant differences in plasma leptin, adiponectin and Hypoadiponectinemia has been associated with obesity, ets, diabetes mellitus, dyslipidemia and hypertension.

A multi-ethnic cohort study in obese children found a negative relationship between adiponectin and CRP, independent of adiposity and insulin resistance. Low levels

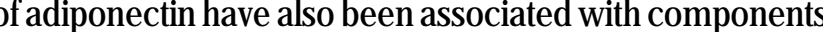
of MetS, such as low HDL cholesterol and high triglycerides. Hypoadiponectinemia appears to be related to the mild degree of chronic inflammatory status that occurs in obesity.

In our study there was a negative correlation between adiponectin and MetS. After three months of diet and physical activity, improvements in BMI and adiponectin concentrations were noticed. In previous studies, adiponectin concentrations were shown to increase as a result of weight loss from diet or exercise [12-14] or bariatric surgery [15-18], while other studies found no major impact of body fat reduction on levels of adiponectin [19-23]. This lack of influence might be due to low weight loss, individual variations in plasma adiponectin concentrations, small numbers of subjects or sex differences.

Table 2

PAIRED SAMPLES T -TEST FOR THE ANTHROPOMETRIC AND BIOLOGICAL CHANGES FOLLOWING THE 3 MONTH OF DIET AND PHYSICAL ACTIVITY riteria for Mets. They were put on a patients met the
3. Density plot of adiponectin 
Cook et al. showed a correlation between obesity and a minor degree of inflammation, detecting significantly higher CRP values in obese children [24]. A marked increase in hs-CRP was observed in our study in children with MetS. The conclusion of these findings is that the degree of inflammation that exists in obese children is higher with the presence of MetS and that a positive correlation between hs-CRP and MetS can be established. Reseland et al. found a decrease in plasma leptin concentrations of $5 \%$ after increased physical activity and of $24 \%$ following dietary changes and exercise [25]. The accumulation of triacylglycerol is one of the triggers for modifying the expression of leptin in the adipose tissue. Leptin levels were shown to decrease after fasting and increase after overfeeding [26]. BMI values do not appear to improve after short-term fasting; some authors show ed that leptin levels and energy balance are only modified after one year of dietary change, suggesting the effect of regulating factors other than body fat [27]. Various studies looked into the importance of physical activity in the regulation of leptin, some with discordant results [28, 29]. In the present study, leptin levels and BMI were reduced after diet and physical exercise. The decrease in leptin concentration was statistically significant.

Lifestyle changes such as the ones we used are known to have an effect on carbohydrate metabolism, insulin resistance and hypertension. The adipocyte is able to detect changes in energy homeostasis via insulin, corticoids and epinephrine [30]. Thus, the decrease in leptin levels can be independent of body fat mass [31]. Physical exercise was shown to prevent diabetes in obese children and adolescents [32, 33]. Conducting a study on how long-term physical exercise affects leptin concentrations, Pasman and Saris found that lower leptin concentrations can be achieved at a certain body fat mass with exercise [34, 35]. As we could not establish a positive correlation between leptin and MetS, improving leptin levels alone does not appear to decrease cardiovascular risk.

\section{Conclusions}

Obesity is a chronic inflammatory disorder, in which leptin, adiponectin and CRP play an important role. MetS correlates with high levels of hs-CRP and low levels of adiponectin. Leptin, adiponectin and hs-CRP can be used as predictors for cardiovascular.

Acknowledgements:This research was supported by a grant at Victor Babes, University of Medicine and Pharmacy Timisoara PII-C2-TC2014 Child Obesity-2014 obtained by Ramona Stroescu.

\section{References}

1. M. MANSOUR, Y. E. NASSEF, M. A. SHADY, A. A. AZIZ, AND H. A. EL MALT, Open access Maced. J. Med. Sci., 4, no. 1, p. 118, 2016.

2.F. BONOMINI, L. F. RODELLA, AND R. REZZANI, Aging Dis., 6, no. 2, p. $109,2015$.
3. N. ESSER, S. LEGRAND-POELS, J. PIETTE, A. J. SCHEEN, AND N. PAQUOT, Diabetes Res. Clin. Pract., 105, no. 2, p. 141, 2014.

4. J. AYER, M. CHARAKIDA, J. E. DEANFIELD, AND D. S. CELERMAJER, Eur. Heart J., 36, no. 22, p. 1371, 2015.

5. 0. YOUSUF et al., J. Am. Coll. Cardiol., 62, no. 5, p. 397, 2013.

6. P. LIBBY, Y. OKAMOTO, V. Z. ROCHA, AND E. FOLCO, Circ. J., 74, no. 2, p. $213,2010$.

7. M. MANSOUR et al., J. Clin. Endocrinol. Metab., 10, no. 2, p. 2271, 2015.

8. K. NAKAMURA, J. J. FUSTER, AND K. WALSH, J. Cardiol., 63, no. 4, p. 250, 2014.

9. H. F. LOPES, R. L. KLEIN, W. T. GARVEY, T. GOODFRIEND, AND B.

M. EGAN, Diabetol. Metab. Syndr., 6, no. 1, p. 132, 2014.

10. R. WEISS et al., N. Engl. J. Med., 350, no. 23, p. 2362, 2004.

11. R CORE TEAM, "R: A Language and Environment for Statistical Computing." Vienna, Austria, 2017.

12. J. PRAKASH, B. MITTAL, S. AWASTHI, C. G. AGARWAL, AND N. SRIVASTAVA, Indian J. Clin. Biochem., 28, no. 2, p. 158, 2013.

13. A. GARCIA-HERMOSO, R. J. M. CEBALLOS-CEBALLOS, C. E. POBLETEARO, A. C. HACKNEY, J. MOTA, AND R. RAMIREZ-VÉLEZ, Int. J. Obes., 41, no. 4, p. 475, 2017.

14. J. Z. ILICH, O. J. KELLY, Y. KIM, AND M. T. SPICER, Arch. Ind. Hyg. Toxicol., 65, no. 2, p. 139, 2014.

15. J.-Y. JEON, J. HAN, H.-J. KIM, M. S. PARK, D. Y. SEO, AND Y.-S. KWAK, Integr. Med. Res., 2, no. 4, p. 145, 2013.

16. X. WANG, T. YOU, K. MURPHY, M. F. LYLES, AND B. J. NICKLAS, Med. Sci. Sports Exerc., 47, no. 11, p. 2450, 2015.

17. M. MANCO et al., J. Clin. Endocrinol. Metab., 92, no. 2, p. 483, 2006.

18. T. AUGUET et al., Obesity, 22, no. 1, p. 188, 2014.

19. E. NIGRO et al., Biomed Res. Int., 2014, 2014.

20. H. SARLAK, M. AKHAN, M. CAKAR, O. KURT, E. ARSLAN, AND S. BALTA, J. Intern. Med., 274, no. 6, p. 614, 2013.

21. A. M. XYDAKIS et al., J. Clin. Endocrinol. Metab., 89, no. 6, p. 2697, 2004.

22. T.-N. WANG et al., J. Med. Sci., 29, no. 8, p. 436, 2013.

23. I. GIANNOPOULOU et al., Metab. Exp., 54, no. 7, p. 866, 2005.

24. D. G. COOK et al., Atherosclerosis, 149, no. 1, p. 139, 2000.

25. M. H. ROKLING-ANDERSEN et al., Am. J. Clin. Nutr., 86, no. 5, p. 1293, 2007.

26. V. IZADI, S. SARAF-BANK, AND L. AZADBAKHT, ARYA Atheroscler., 10, no. 5, p. 266, 2014.

27. E. KOREK, H. KRAUSS, M. GIBAS-DORNA, J. KUPSZ, M. PIKATEK, AND J. PIKATEK, 8, no. 6, p. 383, 2013.

28. A. BOUASSIDA et al., J. Sports Sci. Med., 5, no. 2, p. 172, 2006.

29. L. U. MONZILLO et al., Obesity, vol. 11, 9, p. 1048, 2003.

30. R. V CONSIDINE, J. Appl. Physiol., 83, no. 1, p. 3, 1997.

31. H. ZHANG et al., Sci. Rep., 7, 1, p. 17717, 2017.

32. M. MENDELSON et al., Pediatr. Obes., 10, no. 4, p. 311, 2015.

33. K. KARACABEY, J. Int. Med. Res., 37, 5, p. 1472, 2009.

34. W. J. PASMAN AND W. H. SARIS, Obes Res, 4, p. 14s, 1996.

35. K. C. G. GIT AND R. A. H. ADAN, Obes. Rev., vol. 16, no. 3, p. 207, 2015.

$\overline{\text { Manuscript received: } 18.04 .2018}$ 